\title{
Awareness, Attitude and Practices Regarding Cervical Cancer Screening and Vaccination among North Indian Women Population
}

\author{
Malvika Misra1, Vandana Tiwari², Pratima Tripathi2* \\ ${ }^{1}$ Department of Obstetrics and Gynecology, Dr. Ram Manohar Lohia Institute of Medical Sciences, Lucknow, India \\ ${ }^{2}$ Department of Biochemistry, Dr. Ram Manohar Lohia Institute of Medical Sciences, Lucknow, India \\ Email: ^pratimatripathi.lko@gmail.com,drmalvikam@gmail.com,drvandana2166@yahoo.com
}

How to cite this paper: Misra, M., Tiwari, V. and Tripathi, P. (2020) Awareness, Attitude and Practices Regarding Cervical Cancer Screening and Vaccination among North Indian Women Population. Journal of Biosciences and Medicines, 8, 73-88.

https://doi.org/10.4236/jbm.2020.83008

Received: January 29, 2020

Accepted: March 2, 2020

Published: March 5, 2020

Copyright () 2020 by author(s) and Scientific Research Publishing Inc. This work is licensed under the Creative Commons Attribution International License (CC BY 4.0).

http://creativecommons.org/licenses/by/4.0/

\begin{abstract}
Cervical cancer is the most common cancer associated with women in developing countries with $80 \%$ cases reported every year and could be prevented by proper screening and vaccination. The objective of this study was to explore the knowledge, attitudes, and practices of North Indian women visiting Dr. Ram Manohar Lohia Institute of Medical Sciences, Lucknow for cervical cancer screening. This was a cross-sectional study of 300 women attending the Out-patient department (OPD) at Dr. Ram Manohar Lohia Institute of Medical Sciences, Lucknow. We used a validated questionnaire tool comprised of 24 items to collect data through face-to-face interviews between January 2018 and October, 2019. Results are expressed in percentage form for each question in this article. The mean age \pm SD of the participants was $34 \pm$ 10.34 years, they were mostly married $(198 ; 66 \%)$, and had a high school or higher education $(235 ; 78.3 \%)$. Over 66\% (198 participants) were aware of cervical cancer as a disease and had heard about it from various sources like their family, friends, television, print media, radio etc. Most of these participants (66\%) who were aware of Cervical cancer (CX CA) had been able to identify the various established risk factors, signs and symptoms of the disease but only $20 \%$ were aware with Pap smear procedure while almost $70 \%$ didn't know that early detection of this disease is possible. Nearly $53 \%$ (158 participants) believed that CX CA vaccination will protect them against cervical cancer. After explaining all the signs, symptoms, possible modes of transmission and dangers related to the ignorance of cervical cancer screening, 68.3 percent of the women participants agreed to allow their female relatives for CX CA screening and vaccination while $32 \%$ still had certain hesitations related to the screening and vaccination program. The need of the hour is a better-planned program to generate awareness and allow the women
\end{abstract}


candidates to explore the CX CA issue and get themselves and their relatives prepared for screening and vaccination from the deadly disease.

\section{Keywords}

Cervical Cancer, HPV Screening, Human Papillomavirus (HPV) Vaccine

\section{Introduction}

Cervical cancer (CX CA) is the most common cause of cancer and is related to high mortality rate among women worldwide. Developed countries have significantly reported a drop in cervical cancer incidences due to intensive screening programs [1]. But, still, it is the second most common carcinoma among women in developing and underdeveloped countries, accounting for about $80 \%$ of the global economic and health care burden due to this disease [2]. Nearly all cases of cervical cancers can be attributed to human papillomavirus (HPV) infections [3]. Over 120 types of HPV have been identified and 12 types (HPV 16, 18, 31, $33,35,39,45,51,52,56,58$, and 59) show sufficient evidence to be causally linked with the development of cervical cancer [4]. CX CA becomes a deadly disease when it reaches the invasive stages but out of all the female genital tract cancers, it is the only preventable cancer if detected in its early stages. Evidence from the epidemiological and molecular biological studies has established a strong association between human papillomavirus (HPV) serotypes 16 and 18 and the severity of cervical cancer [5] HPV is responsible for more than $90 \%$ of invasive cancer and $80 \%$ of precancerous lesions in the cervix [6]. Hence, screening for HPV virus infection may help in attenuating the progression of the precancerous lesions to invasive malignancy to a great extent.

In India, cervical cancer is one of the leading malignancies among women, with about 130,000 new cases and 74,000 deaths every year [7] accounting for $30 \%$ of global cervical cancer mortality [8]. India's cervical cancer age-standardized incidence rate $(30.7$ per 100,000$)$ and age-standardized mortality rate $(17.4$ per 100,000) are the highest in South Central Asia [9] [10]. Data from some cancer registries suggest that there may have been a slight decline in cervical cancer incidence in the recent years. However, the absolute incidence is still very high, especially in the rural areas, and the number of cases is increasing due to high population growth every year [10]. Although cervical cancer can be treated effectively if detected in Stage I and II, it does not show any symptom in these stages. In the absence of a screening program, most of these cases come to the attention of doctors at an advanced stage when hardly any curative management is possible. Cervical cancer is a subject that is not freely discussed in India because of the cultural taboos prevailing in different forms across the country. There is an urgent need to educate the Indian women about the various aspects of cervical cancer and the early detection measures. Furthermore, it's important to find out the willingness of women to utilize screening services and to comply 
with follow-up treatment protocol by breaking their mental and superstitious arena. Global evidence demonstrates that the key to reducing cervical cancer morbidity and mortality is early detection coupled with timely treatment of cervical precancerous lesions [10]. Cervical cytology often referred to as the Papanicolaou test (Pap test) is perhaps the most well-known of available screening methods [11]. The present study was conducted to find out awareness of cervical carcinoma, early detection measures, and willingness of the North Indian women to utilize screening and vaccination services available at the medical centers.

\section{Materials and Methods}

This cross-sectional study was conducted between January 2018 and October, 2019 at Dr. Ram Manohar Lohia Institute of Medical Sciences, Lucknow, India. In the present study 300 women age 30 to 65 years, from north India were enrolled on their visit to the OPD after informed written consent.

Sample size collection is done using the following formula:

$$
n=(Z)_{1-\alpha / 2}^{2} P(1-P) / d^{2}
$$

$n=$ Sample size, $P=$ Prevalence, $\alpha=$ Error, $d=$ Degree of freedom.

$Z=$ Differentiation coefficient (1.96 or 2).

Inclusion criteria: Patient group comprised of 300 females subjects of age 20 60 years visiting OPD.

Exclusion criteria: Females with $<18$ years of age, previously ill, handicapped, pregnant women will be excluded from the study.

A pretested semi-structured interview schedule was used to collect information. The interview schedule had three parts. The first part had details about socio-demographic variables (age, education, marital status, background, occupation score and family income). The second part had questions about the gynecological history (age of marriage, number of live children, family structure, number of failed pregnancies and the type of health facilities if available at their urban/rural set up where the participant lives) of the participant. The third part had questions focused to find out the awareness of risk factors, signs and symptoms of cervical cancer, its detection methods, screening, vaccination and prevention. The questionnaire used in this study was prepared after literature search and previously established facts about cervical cancer. The questionnaire was pretested before the actual survey.

The questionnaire used in this study was filled and data was collected through direct interaction with the female subjects visiting the OPD on daily basis at Dr. Ram Manohar Lohia Institute of Medical Sciences. The collected data were analyzed using standard statistical formula using the SPSS statistical analysis software, version 15.0 (SPSS, Chicago, IL, USA). The questionnaire is attached as Appendix at the last page of this article.

\section{Result}

Table 1 shows the socio-demographic characteristics of the 300 women population 
Table 1. Socio-demographic characteristics of study population.

\begin{tabular}{|c|c|c|}
\hline Variable & Frequency (numbers) & Percentage (\%) \\
\hline \multicolumn{3}{|l|}{ Age (years) } \\
\hline $21-30$ & 159 & 53 \\
\hline $31-40$ & 103 & 34.3 \\
\hline $41-50$ & 30 & 10 \\
\hline $51-60$ & 8 & 2.7 \\
\hline$\geq 60$ & - & - \\
\hline Total & 300 & 100 \\
\hline \multicolumn{3}{|l|}{ Marital status } \\
\hline Married & 198 & 66 \\
\hline Single & 83 & 27.7 \\
\hline Widow/divorced/separated & 19 & 6.3 \\
\hline Total & 300 & 100 \\
\hline \multicolumn{3}{|l|}{ Background } \\
\hline Rural & 210 & 70 \\
\hline Urban & 90 & 30 \\
\hline Total & 300 & 100 \\
\hline \multicolumn{3}{|l|}{ Education } \\
\hline Illiterate & 65 & 21.7 \\
\hline Below matriculation & 105 & 35 \\
\hline Intermediate or post high school diploma & 75 & 25 \\
\hline Graduate & 42 & 14 \\
\hline Postgraduate & 13 & 4.3 \\
\hline Total & 300 & 100 \\
\hline \multicolumn{3}{|l|}{ Occupation score } \\
\hline Unemployed (Score 1) & 109 & 36.3 \\
\hline Unskilled/semi-skilled worker (Score 2) & 75 & 25 \\
\hline Skilled worker (Score 3) & 60 & 20 \\
\hline Clerical/shop owner/farmer (Score 4) & 40 & 13.3 \\
\hline Professional (Score 5) & 16 & 5.3 \\
\hline Total & 300 & 100 \\
\hline \multicolumn{3}{|l|}{ Family monthly income } \\
\hline$<3000($ Score 1$)$ & 101 & 33.7 \\
\hline $3000-5000$ (Score 2$)$ & 79 & 26.3 \\
\hline $5001-10,000($ Score 3$)$ & 60 & 20 \\
\hline $10,001-20,000($ Score 4$)$ & 40 & 13.3 \\
\hline Above 20,000 (Score 5) & 20 & 6.7 \\
\hline Total & 300 & 100 \\
\hline
\end{tabular}

enrolled in this study. As shown, mean age of the study participants was 34.14 years \pm 6.59 standard deviation with majority (53\%) being in the age group of 21 - 30 years and most of them (66\%) were married. $70 \%$ of the enrolled subjects belonged to rural set up, $21.7 \%$ were illiterate while $60 \%$ of the subjects were educated below graduation. $36.3 \%$ of the study population was unemployed (score 1) while half of them had minimal source of earning with unskilled and low wages jobs (score 2 - 4). Mean income per capita was quite less with $60 \%$ of the population having monthly per capita income of less than 5000 (score 1 - 2). All the data presented in Table 1, shows that the study population enrolled in this current study belonged to financially weaker section because most of them 
were from rural setup with low education and low paying jobs. Since Indian villages still have the majority population getting married at an early age, the data in Table 1 represent the same.

Table 2 shows the gynecological history of the respondents enrolled in this study. As shown, more than half (84.4\%) of the subjects got married before 30 years and $50.7 \%$ had 3 or more than 3 live children. $41 \%$ of the enrolled subjects belonged to large family set up with more than 5 persons living together. $63.7 \%$ of these people were dependent on local health workers, compounders and chemists for their health issues because they did not have access to proper nursing and medical staff. Since most of the study subjects (64\%) got married within 18 - 27 years, we can see the percentage of failed pregnancies with different methods of miscarriages or pregnancy termination to be quite high (76.3\%). Out of this, $26.3 \%$ of the subjects met spontaneous miscarriages while $50 \%$ had their pregnancies terminated by induced, medical and surgical termination methods.

Table 2. Gynecological history of the respondents enrolled in the study.

\begin{tabular}{|c|c|c|}
\hline Variable & Frequency (numbers) & Percentage (\%) \\
\hline \multicolumn{3}{|l|}{ Approximate age of marriage } \\
\hline $18-23$ years & 102 & 34 \\
\hline $23-27$ years & 92 & 30.7 \\
\hline 27 - 30 years & 59 & 19.7 \\
\hline $30-35$ years & 35 & 11.7 \\
\hline$>35$ years & 12 & 04 \\
\hline Total & 300 & 100 \\
\hline \multicolumn{3}{|l|}{ No. of previous live children } \\
\hline Nil & 45 & 15 \\
\hline 1 & 35 & 11.7 \\
\hline 2 & 68 & 22.7 \\
\hline 3 & 81 & 27 \\
\hline More than 3 & 71 & 23.7 \\
\hline Total & 300 & 100 \\
\hline \multicolumn{3}{|l|}{ Family structure (nuclear/joint) } \\
\hline 2 & 56 & 18.7 \\
\hline $2-5$ & 121 & 40.3 \\
\hline$>5$ & 123 & 41 \\
\hline Total & 300 & 100 \\
\hline \multicolumn{3}{|c|}{ Health facilities at the rural/urban setting } \\
\hline Local Health worker (LHW) & 95 & 31.7 \\
\hline Compounder & 43 & 14.3 \\
\hline Chemist & 53 & 17.7 \\
\hline Proper nursing and medical staff & 109 & 36.3 \\
\hline Total & 300 & 100 \\
\hline \multicolumn{3}{|c|}{$\begin{array}{l}\text { Any previous history of miscarriage/pregnancy } \\
\text { termination }\end{array}$} \\
\hline Spontaneous & 79 & 26.3 \\
\hline Induced & 72 & 24 \\
\hline Medical termination method & 51 & 17 \\
\hline Surgical termination method & 27 & 09 \\
\hline None & 71 & 23.7 \\
\hline Total & 300 & 100 \\
\hline
\end{tabular}


All the data presented in Table 2 show that most of the study population enrolled in this current study belonged to early marriage category and hence had higher number of live pregnancies with most of them having history of terminated pregnancies and miscarriages which were either induced or spontaneous.

As per the observations in Table 3, out of the 300 women interviewed, $85 \%$ ( $n$ $=254$ ) were aware of cancer as a disease. However, a little more than half of women $(66 \%, n=198)$ were aware of cervical cancer. The proportion of women who were aware of cervical carcinoma increased as the literacy status increased, and this association was statistically significant. Similarly, those who had a higher per capita income were more aware of cervical cancer as compared to those belonging to a family with a lower per capita income and this difference was also statistically significant. Statistically, significant association was also seen between use of a family planning method and awareness about this particular cancer.

\section{Source of information about Cervical Cancer}

Most of the respondents $(40.4 \%, n=80)$ had heard about cervical cancer from friends and relatives. Other sources of knowledge were health-care personnel (23\%), print media (10\%), television (20\%), and radio (7\%).

\section{Knowledge about established risk factors of cervical cancer}

The women who were aware of cervical cancer $(n=198)$ were asked about the risk factors of this cancer. Twenty-three percent of women $(n=45)$ mentioned family history as a risk factor. Thirty-three percent $(n=65)$ women identified early marriage followed by multiple pregnancies as the risk factor for CX CA. Over $32 \%(n=63)$ of participants rightly mentioned uterine infection especially HPV infection as the most common risk of CX CA. Other established risk factors which were rightly interpreted were multiparty $(3 \%, n=6)$, oral contraceptives $(4.5 \%, n=9)$, smoking $(5.1 \%, n=10)$ as a risk factor for cervical cancer.

\section{Knowledge of signs and symptoms}

Out of 198 participants who were aware of cervical cancer as a disease, forty three percent $(n=85)$ of them were aware that bleeding between two menstrual cycles could be a sign of cervical cancer. Twenty-two percent $(n=43)$ of study population mentioned vaginal discharge and seventeen percent $(n=33)$ identified pain in the pelvic region as a symptom. Almost nineteen percent of the study population were aware of post-coital bleeding and discomfort during intercourse, pain in pelvic region, weight and appetite loss $(n=37)$ as signs of this cancer.

\section{Knowledge about early detection methods}

Only $30 \%$ of the participants $(n=161)$ were aware that cervical cancer can be detected early. Eighty three respondents (20\%) said that it could be detected by Pap smear. Ten percent of the women thought it could be detected by clinical examination by a doctor. Seventy percent of women $(n=139)$ thought that the early detection for this particular form of cancer is not possible.

\section{Willingness to participate in a cervical cancer screening program}

All study participants were explained about the importance and procedure of the established screening test for carcinoma cervix and were asked if such a facility 
Table 3. Awareness of cervical cancer screening and vaccination.

\begin{tabular}{|c|c|c|}
\hline Variables & Frequency & Percentage \\
\hline \multicolumn{3}{|l|}{ Are you aware of cancer } \\
\hline Yes & 254 & 84.7 \\
\hline No & 46 & 15.3 \\
\hline Total & 300 & 100 \\
\hline \multicolumn{3}{|l|}{ Are you aware of cervical cancer } \\
\hline Yes & 198 & 66 \\
\hline No & 102 & 34 \\
\hline Total & 300 & 100 \\
\hline \multicolumn{3}{|c|}{ If yes, how do you know about it (CX CA) } \\
\hline Friends and relatives & 80 & 40.4 \\
\hline Health-care personnel & 46 & 23.2 \\
\hline Print media & 20 & 10.1 \\
\hline Television & 39 & 19.7 \\
\hline Radio & 13 & 6.6 \\
\hline Total & 198 & 100 \\
\hline \multicolumn{3}{|l|}{ Do you use family planning methods? } \\
\hline Yes & 230 & 76.7 \\
\hline No & 70 & 23.3 \\
\hline Total & 300 & 100 \\
\hline \multicolumn{3}{|c|}{ Knowledge about established risk factors of cervical cancer } \\
\hline Family history & 45 & 22.7 \\
\hline Early marriage & 35 & 17.7 \\
\hline Multiple full term pregnancies & 30 & 15.2 \\
\hline Uterine infections & 23 & 11.6 \\
\hline HPV infections & 40 & 20.2 \\
\hline Smoking & 10 & 5.1 \\
\hline Oral contraceptives & 9 & 4.5 \\
\hline Multiple sex partners & 6 & 3.0 \\
\hline Total & 198 & 100 \\
\hline \multicolumn{3}{|l|}{ Knowledge of signs and symptoms } \\
\hline Menstrual abnormality & 85 & 42.9 \\
\hline Vaginal discharge & 43 & 21.7 \\
\hline Pain & 33 & 16.7 \\
\hline Others* & 37 & 18.7 \\
\hline Total & 198 & 100 \\
\hline \multicolumn{3}{|c|}{ Knowledge about early detection methods } \\
\hline PAP smear test & 39 & 19.7 \\
\hline Clinical examination & 20 & 10.1 \\
\hline Early detection not possible & 139 & 70.2 \\
\hline Total & 198 & 100 \\
\hline \multicolumn{3}{|c|}{ How often do you think you need PAP smear test } \\
\hline No idea & 126 & 42 \\
\hline 6 monthly & 56 & 18.7 \\
\hline 1 yearly & 24 & 8 \\
\hline 3 yearly & 94 & 31.3 \\
\hline Total & 300 & 100 \\
\hline \multicolumn{3}{|c|}{ How many times have you been screened } \\
\hline Never & 178 & 59.3 \\
\hline Once & 86 & 28.7 \\
\hline Twice & 36 & 12 \\
\hline Thrice & - & - \\
\hline Total & 300 & 100 \\
\hline
\end{tabular}




\section{Continued}

\begin{tabular}{|c|c|c|}
\hline \multicolumn{3}{|c|}{$\begin{array}{l}\text { Willingness to participate in a cervical cancer screening and } \\
\text { vaccination program }\end{array}$} \\
\hline Yes & 205 & 68.3 \\
\hline No & 95 & 31.7 \\
\hline Total & 300 & 100 \\
\hline \multicolumn{3}{|l|}{ If no, reason } \\
\hline - I am against all vaccinations & 15 & 15.8 \\
\hline - The vaccine is not safe & 10 & 10.5 \\
\hline - The vaccine may have side effect & 23 & 24.2 \\
\hline - Religious reasons & 24 & 25.2 \\
\hline - HPV vaccination not necessary & 15 & 15.8 \\
\hline - Family restrictions/other reasons (not specified) & 08 & 8.5 \\
\hline Total & 95 & 100 \\
\hline \multicolumn{3}{|l|}{ Mode of HPV transmission } \\
\hline Physical contact & 50 & 16.7 \\
\hline Aerosol/air droplet & 76 & 25.3 \\
\hline Sexual intercourse with multiple partners & 129 & 43 \\
\hline No knowledge & 45 & 15 \\
\hline Total & 300 & 100 \\
\hline \multicolumn{3}{|l|}{ CX CA vaccination protects against } \\
\hline Cervical cancer & 158 & 52.7 \\
\hline Anal cancer & 23 & 7.7 \\
\hline Vulvar cancer & 17 & 5.7 \\
\hline Warts & 08 & 2.7 \\
\hline HIV/AIDS & 10 & 3.3 \\
\hline Breast cancer & 30 & 10 \\
\hline No knowledge & 54 & 18 \\
\hline Total & 300 & 100 \\
\hline \multicolumn{3}{|c|}{ Would you allow your daughter or close relatives to get HPV } \\
\hline vaccination & 215 & 68.3 \\
\hline Yes & 85 & 31.7 \\
\hline No & 300 & 100 \\
\hline If not (reason) & 25 & 29.4 \\
\hline - I am against any vaccination & 23 & 27.1 \\
\hline - Family restrictions & 14 & 16.5 \\
\hline \multicolumn{3}{|c|}{ - The vaccine will initiate early sexual desires/activity in young girls } \\
\hline - No one in my family is having CX CA & 15 & 17.6 \\
\hline - Others (reason not known) & 08 & 9.4 \\
\hline Total & 85 & 100 \\
\hline
\end{tabular}

*Others included post-coital bleeding, bladder and rectal involvement, weight loss, loss of appetite and pelvic pain.

was available to them whether they would be willing to undergo such a test. Only sixty eight percent $(n=205)$ of the study population were willing to go through a screening test for cancer cervix. It was found that willingness to participate was higher with higher literacy status and use of family planning methods. Study participants who were aware of at least one correct risk factor or one sign/symptom or possibility of early detection of this particular form of cancer were more willing to participate in screening program than people who were not aware of these aspects. No significant association was found between willingness to participate and participant's awareness of cervical cancer as a form of cancer, age, and in- 
come per capita. Those who were still not willing to undergo this test $(n=95$, $32 \%)$ mentioned different reasons like being against vaccination, religious reasons, family restrictions etc. for their denial to be screened and vaccinated.

\section{Knowledge about mode of HPV transmission and protection by $C X C A$} vaccination

Out of the three hundred women participants enrolled in the study, only forty three percent rightly identified sexual intercourse with multiple partners as the mode of HPV transmission. Forty two percent were under the impression that HPV could be transmitted either by physical contact or through air/aerosol droplets while fifteen percent had no knowledge about this infection. When asked about the various types of abnormalities against which CX CA vaccination provides protection, fifty three percent $(n=158)$ participants identified that it provides protection against cervical cancer while eighteen percent $(n=54)$ had no knowledge about this, twenty percent $(n=88)$ identified that it provides protection against anal cancer, vulvar cancer, warts, HIV/IDS and breast cancer. After explaining all the signs, symptoms, possible modes of transmission and dangers related to the ignorance of cervical cancer screening, 68.3 percent of the women participants agreed to allow their female relatives for CX CA screening and vaccination while $32 \%$ still had certain hesitations related to the screening and vaccination program. This calls for a better, extensive awareness program to generate awareness and allow the women candidates to explore the issue and get themselves and their relatives prepared for CX CA screening and vaccination from the deadly disease.

\section{Discussion}

In the present study, we found that only $66 \%$ of the respondents were aware of cervical cancer as a disease and those who were aware were educated and have a higher per capita income than those who were not aware. Subjects enrolled in the present study had very poor knowledge about established risk factors of cervical cancer which is consistent with findings of some other studies [12]. Out of $30 \%$ of women who were aware of cervical cancer, $20 \%$ were aware of Pap smear as one of the screening techniques for this disease. This finding of our study concurred with a similar study [10]. Two-third of the study population who were aware of cervical cancer had heard about it from neighbors and relatives. Television, a very popular mass media, was mentioned as a source of information only by $20 \%$ of study population. Similar findings were reported from a study done in Mangalore region in India, which mentioned television as a source of information for cervical cancer by only $14 \%$ [12] [13].

Our study coincided with a similar study and revealed that willingness to participate in a screening procedure was higher among those who were educated and had used method of family planning [13]. We found that women who were aware of the risk factors, signs and symptoms, of cervical cancer were willing to participate than those who were not. All the women (100\%) who were aware that 
early detection is possible were willing to participate in a screening program. Studies on various aspects of knowledge about cervical cancer revealed that the lack of knowledge about this disease appears to be an important factor to determine women's willingness to participate in cervical cancer screenings and vaccination program [14] [15].

Till now, there is no established national screening program for cervical cancer in India. Screening programs have been shown to reduce the incidence and mortality from cervical cancer in many developed countries [16] [17]. The National Programme for Prevention and Control of Cancer, Diabetes, Cardio Vascular Diseases, and Stroke (NPCDCS) advocates for opportunistic and targeted screening of women of the age group $>30$ years at district NCD clinic for early detection of cervix cancer [18]. Success of any screening program primarily depends on prior-understanding of the factors that determine women's willingness to participate in the screening procedures. Association between awareness about cervical cancer and willingness to participate in cervical cancer screening and vaccination program has been documented in this study are supported by similar studies [19] [20]. These findings emphasize the need for dissemination of knowledge about cervical cancer to ensure the uptake of HPV screening and vaccination services. It was also found that the primary source of CXCA related knowledge to the subjects enrolled in the study was from relatives and neighbors. It has been reported that anxiety associated with cervical cancer screening results from insufficient information or magnification of different facts [21]. Hence there is a need to disseminate the correct knowledge keeping in view the sensitivity of the issue that is affected by religious and cultural beliefs. Popular mass media and commercials and trained nonmedical personnel like accredited social health activists who are females and are from the same or nearby community can be used as a key link for raising awareness about the risk factors, signs, symptoms, screening procedures and vaccination available for CXCA [22].

\section{Conclusion and Recommendations}

Women in North India were ignorant about risk factors, signs and symptoms, and early detection measure of cervical cancer. Specific knowledge on cervical cancer and its early detection in precancerous stage and subsequent treatment is the immediate need of the hour. The limitation of this study was that it was a quantitative study and hence psychosocial and cultural reasons for not willing to participate in screening test could not be explored in depth. Other limitations were the study participants who were from rural background and belonged to low income and less educated group, and so the results may not be generalized to other parts of India. Our study recommends an urgent need to educate women in north India on different aspects of cervical cancer, the associated risks, and its screening and vaccination facilities available in the medical centers. Special efforts would be required for the core group of illiterate women for a better impact on screening acceptance. We recommend the drafting of proper policy 
guidelines that will help the women in developing countries to accept the screening and vaccination of cervical cancer without any preset notion and thus could take care of themselves and their relatives against this deadly disease.

\section{Limitations of This Study}

The study has limitation of being completely based on the choice of the participants to enroll in the study. There was no compulsion to any of the participant from any community. If any of the participants chose to withdraw from the study, she was free to do so.

\section{Acknowledgements}

The authors acknowledge the encouragement and infrastructural support provided by DRMLIMS to conduct the study.

\section{Conflicts of Interest}

The authors declare no conflict of interest to compete.

\section{References}

[1] Cervical Cancer: Estimated Incidence, Mortality and Prevalence Worldwide in 2012. http://globocan.iarc.fr/old/FactSheets/cancers/cervix-new.asp

[2] Global Burden of Cancer in Women. Current Status, Trends, and Interventions. https://www.cancer.org/content/dam/cancer-org/research/cancer-facts-and-statistic $\underline{\text { s/global-cancer-facts-and-figures/global-burden-ofcancer-in-women.pdf }}$

[3] Ferlay, J., Ervik, M., Lam, F., Colombet, M., Mery, L., Piñeros, M., Znaor, A., Soerjomataram, I. and Bray, F. (2018) Global Cancer Observatory: Cancer Today. International Agency for Research on Cancer, Lyon, France.

[4] Burd, E.M. (2003) Human Papillomavirus and Cervical Cancer. Clinical Microbiology Reviews, 16, 1-17. https://doi.org/10.1128/CMR.16.1.1-17.2003

[5] Denny, L., Herrero, R., Levin, C. and Kim, J.J. (2015) Cervical Cancer. In: Gelband, H., Jha, P., Sankaranarayanan, R. and Horton, S., Eds., Cancer. Disease Control Priorities, Third Edition, Volume 3, World Bank, Washington DC, 69-84. https://doi.org/10.1596/978-1-4648-0349-9_ch4

[6] Jassim, G., Obeid, A. and Al Nasheet, H.A. (2018) Knowledge, Attitudes, and Practices Regarding Cervical Cancer and Screening among Women Visiting Primary Healthcare Centres in Bahrain. BMC Public Health, 18, Article No. 128. https://doi.org/10.1186/s12889-018-5023-7

[7] Ferlay, J., Bray, F., Pisani, P. and Parkin, D.M. (2004) Cancer Incidence, Mortality and Prevalence Worldwide, GLOBOCAN 2002. IARC Cancer Base No. 5 Version 2.0. IARC, Lyon.

[8] Drain, P.K., Holmes, K.K., Hughes, J.P. and Koutsky, L.A. (2002) Determinants of Cervical Cancer Rates in Developing Countries. International Journal of Cancer, 100, 199-205. https://doi.org/10.1002/ijc.10453

[9] Sankaranarayanan, R., Budukh, A.M. and Rajkumar, R. (2001) Effective Screening Programmes for Cervical Cancer in Low- and Middle-Income Developing Countries. Bulletin of the World Health Organization, 79, 954-962.

[10] Patra, S., Upadhyay, M. and Chhabra, P. (2017) Awareness of Cervical Cancer and 
Willingness to Participate in Screening Program: Public Health Policy Implications. Journal of Cancer Research and Therapeutics, 13, 318-323. https://doi.org/10.4103/0973-1482.187279

[11] Moyer, V.A. (2012) U.S. Preventive Services Task Force. Screening for Cervical Cancer: U.S. Preventive Services Task Force Recommendation Statement. Annals of Internal Medicine, 156, 880-891. https://doi.org/10.7326/0003-4819-156-12-201206190-00424

[12] Tripathi, N., Kadam, Y.R., Dhobale, R.V. and Gore, A.D. (2014) Barriers for Early Detection of Cancer amongst Indian Rural Women. South Asian Journal of Cancer, 3, 122-127. https://doi.org/10.4103/2278-330X.130449

[13] Asthana, S. and Labani, S. (2013) Factors Associated with Attitudes of Rural Women toward Cervical Cancer Screening. Indian Journal of Community Medicine, 38, 246-248. https://doi.org/10.4103/0970-0218.120163

[14] Jia, Y., Li, S., Yang, R., Zhou, H., Xiang, Q., Hu, T., et al. (2013) Knowledge about Cervical Cancer and Barriers of Screening Program among Women in Wufeng County, a High-Incidence Region of Cervical Cancer in China. PLoS ONE, 8, e67005. https://doi.org/10.1371/journal.pone.0067005

[15] Ansink, A.C., Tolhurst, R., Haque, R., Saha, S., Datta, S. and van den Broek, N.R. (2008) Cervical Cancer in Bangladesh: Community Perceptions of Cervical Cancer and Cervical Cancer Screening. Transactions of the Royal Society of Tropical Medicine and Hygiene, 102, 499-505. https://doi.org/10.1016/j.trstmh.2008.01.022

[16] Breen, N., Wagener, D.K., Brown, M.L., Davis, W.W. and Ballard-Barbash, R. (2001) Progress in Cancer Screening over a Decade: Results of Cancer Screening from the 1987, 1992, and 1998 National Health Interview Surveys. Journal of the National Cancer Institute, 93, 1704-1713. https://doi.org/10.1093/jnci/93.22.1704

[17] Nygård, J.F., Skare, G.B. and Thoresen, S.Ø. (2002) The Cervical Cancer Screening Programme in Norway, 1992-2000: Changes in Pap Smear Coverage and Incidence of Cervical Cancer. Journal of Medical Screening, 9, 86-91. https://doi.org/10.1136/jms.9.2.86

[18] Peto, J., Gilham, C., Fletcher, O. and Matthews, F.E. (2004) The Cervical Cancer Epidemic That Screening Has Prevented in the UK. The Lancet, 364, 249-256. https://doi.org/10.1016/S0140-6736(04)16674-9

[19] Wallington, S.F., Luta, G., Noone, A.M., Caicedo, L., Lopez-Class, M., Sheppard, V., et al. (2012) Assessing the Awareness of and Willingness to Participate in Cancer Clinical Trials among Immigrant Latinos. Journal of Community Health, 37, 335-343. https://doi.org/10.1007/s10900-011-9450-y

[20] Ndikom, C.M. and Ofi, B.A. (2012) Awareness, Perception and Factors Affecting Utilization of Cervical Cancer Screening Services among Women in Ibadan, Nigeria: A Qualitative Study. Reproductive Health, 9, Article No. 11. https://doi.org/10.1186/1742-4755-9-11

[21] Baileff, A. (2000) Cervical Screening: Patients' Negative Attitudes and Experiences. Nursing Standard, 14, 35-37. https://doi.org/10.7748/ns2000.07.14.44.35.c2880

[22] Hussain, S.M. (2013) Cancer Control in South Asia: Awareness Is Key to Success. South Asian Journal of Cancer, 2, 55-56. https://doi.org/10.4103/2278-330X.110480 


\section{Appendix}

\section{Questionnaire}

Part-I: Socio-demographic characteristics of study population.

1) Age (years)

$21-30$

$31-40$

$41-50$

$51-60$

$\geq 60$

2) Marital status

Married

Single

Widow/divorced/separated

3) Background

Rural

Urban

4) Education

Illiterate

Below matriculation

Intermediate or post high school diploma

Graduate

Postgraduate

5) Occupation score

Unemployed (Score 1)

Unskilled/semi-skilled worker (Score 2)

Skilled worker (Score 3)

Clerical/shop owner/farmer (Score 4)

Professional (Score 5)

6) Family monthly income

$<3000$ (Score 1)

3000 - 5000 (Score 2)

$5001-10,000$ (Score 3)

10,001 - 20,000 (Score 4)

Above 20,000 (Score 5)

Part II: Gynecological history of the respondents enrolled in the study

7) Approximate age of marriage

18 - 23 years

$23-27$ years

27-30 years

30 - 35 years

$>35$ years

8) No. of previous live children

Nil 
3

More than 3

9) Family structure (nuclear/joint)

2

$2-5$

$>5$

10) Health facilities at the rural/urban setting

Local Health worker (LHW)

Compounder

Chemist

Proper nursing and medical staff

11) Any previous history of miscarriage/pregnancy termination Spontaneous

Induced

Medical termination method

Surgical termination method

None

\section{Part III: Awareness of cervical cancer screening and vaccination}

12) Are you aware of cancer?

Yes

No

13) Are you aware of cervical cancer?

Yes

No

If yes, how do you know about it (CX CA)

Friends and relatives

Health-care personnel

Print media

Television

Radio

14) Do you use family planning methods?

Yes

No

15) Knowledge about established risk factors of cervical cancer Family history

Early marriage

Multiple full term pregnancies

Uterine infections

HPV infections

Smoking

Oral contraceptives 
Multiple sex partners

16) Knowledge of signs and symptoms

Menstrual abnormality

Vaginal discharge

Pain

Others (post-coital bleeding, bladder and rectal involvement, weight loss, loss of appetite and pelvic pain)

17) Knowledge about early detection methods

PAP smear test

Clinical examination

Early detection not possible

18) How often do you think you need PAP smear test?

No idea

6 monthly

1 yearly

3 yearly

19) How many times have you been screened?

Never

Once

Twice

Thrice

20) Willingness to participate in a cervical cancer screening program

Yes

No

If no, reason

I am against all vaccinations

The vaccine is not safe

The vaccine may have side effect

Religious reasons

HPV vaccination not necessary

Family restrictions/other reasons (not specified)

21) Mode of HPV transmission

Physical contact

Aerosol/air droplet

Sexual intercourse

No knowledge

22) CX CA vaccination protects against

Cervical cancer

Anal cancer

Vulvar cancer

Warts

HIV/AIDS

Breast cancer 
No knowledge

23) Would you allow your daughter or close relatives to get HPV vaccination?

Yes

No

If not (reason)

I am against any vaccination

Family restrictions

The vaccine will initiate early sexual desires/activity in young girls

No one in my family is having CX CA

Others (reason not known) 